\title{
Serum Beta-human Chorionic Gonadotropin and Lipid Profile in Early Second Trimester as Predictor of Pregnancy-induced Hypertension
}

\author{
${ }^{1}$ Sanyukta S Dawle, ${ }^{2}$ Anuja V Bhalerao
}

\begin{abstract}
Objective: The study aims at testing the hypothesis that women with high serum beta-human chorionic gonadotropin ( $\beta-\mathrm{hCG}$ ) and serum lipid profile levels in early second trimester have risk of developing pregnancy-induced hypertension and poor maternal and neonatal outcome.
\end{abstract}

Materials and methods: Serum $\beta$-hCG and lipid profile was done in 400 antenatal women between 12 and 24 weeks of gestation and were followed up till delivery. Assessment of serum $\beta$-hCG and serum lipids and their predictability for development of pregnancy-induced hypertension and its effect on maternal and fetal outcome were noted.

Results: Women with high serum $\beta$-hCG levels at 12 to 24 weeks of gestation have 1.67 times more risk of developing pregnancy-induced hypertension $(p=0.035)$, and poor maternal and perinatal outcome. Raised total cholesterol (TC), triglycerides (TGs), low-density lipoprotein (LDL), very lowdensity lipoprotein (VLDL), TC/high-density lipoprotein (HDL) and LDL/HDL are important risk factors for development of pregnancy-induced hypertension. The mean TC level in women with pregnancy-induced hypertension was $210.1304 \pm 50.7392$ as compared with $178.0908 \pm 47.0994$ in normotensive women. The difference in levels of TC $(p<0.001)$, TG $(p=0.0037)$, LDL $(p<0.001)$, VLDL $(p=0.0193)$, TC/HDL $(p<0.001)$, and LDL/HDL $(p<0.001)$ in both the groups was statistically highly significant.

Conclusion: Maternal dyslipidemia and elevated maternal serum $\beta$-hCG at early second trimester are very good noninvasive predictors of pregnancy-induced hypertension. The maternal and perinatal outcome was directly proportional to levels of serum $\beta$-hCG and lipid profile.

Keywords: Beta-human chorionic gonadotropin, Lipid profile, Pregnancy-induced hypertension.

How to cite this article: Dawle SS, Bhalerao AV. Serum Betahuman Chorionic Gonadotropin and Lipid Profile in Early Second Trimester as Predictor of Pregnancy-induced Hypertension. J South Asian Feder Obst Gynae 2018;10(1):33-39.

\footnotetext{
${ }^{1}$ Senior Resident, ${ }^{2}$ Associate Professor

1,2Department of Obstetrics and Gynecology, NKP Salve Institute of Medical Sciences \& Research Center, Nagpur, Maharashtra India

Corresponding Author: Sanyukta S Dawle, Senior Resident Department of Obstetrics and Gynecology, NKP Salve Institute of Medical Sciences \& Research Center, Nagpur, Maharashtra India, Phone: +917122748646, e-mail: sanyukta.dawle@yahoo. com
}

Source of support: Nil

Conflict of interest: None

Date of received: 15 January 2018

Date of acceptance: 25 February 2018

Date of publication: May 2018

\section{INTRODUCTION}

Hypertensive disorder of pregnancy is an enigmatic condition despite exhaustive research, and is associated with high maternal and perinatal mortality and morbidity. This remains a subject of great clinical relevance and intense interest and is a day-to-day problem for each and every obstetrician.

Pregnancy-induced hypertension occurs in approximately 3 to $5 \%$ of pregnancies and is still a major cause of both fetal and maternal morbidity and mortality worldwide. ${ }^{1}$ Overall, the incidence of preeclampsia ranges from 5 to $15 \%$. In India, the incidence of preeclampsia is 8 to $10 \%$ of all the pregnancies. Incidence in primigravidae is $10 \%$ and that in multigravidae is $5 \%$.

Preeclampsia is best described as a pregnancy-specific syndrome unique to humans, which virtually affects every organ system. Although physicians for millennia have recognized preeclampsia, relatively little is known about its pathogenesis and prevention. The primary concern about elevated blood pressure relates to the potential harmful effects on both mother and fetus. These potential adverse effects range in severity from trivial to life threatening.

Preeclampsia is a multisystem disorder of unknown etiology that is unique to human pregnancy and is characterized by abnormal vascular response to placentation associated with increased systemic vascular resistance, enhanced platelet aggregation, activation of coagulation system, and endothelial dysfunction. Additionally, renal, hepatic, coagulation, and central nervous system can be affected.

Preeclampsia is associated with increased risk of maternal mortality and maternal morbidities like convulsions, abruptio placentae, acute renal failure, cerebrovascular complications, liver hemorrhage and disseminated intravascular coagulation (DIC). ${ }^{2}$ 
The infants of preeclamptic mothers have a significantly higher incidence of prematurity, somatic growth retardation, thrombocytopenia, delayed adaptation, patent ductus arteriosus, and gastrointestinal hypomotility. ${ }^{3}$

Despite extensive research and improved technology in recent decades, the etiology and pathophysiology of the syndrome remain enigmatic. So, there are no rational preventive or therapeutic interventions available.

A careful consideration of various factors and individualization of cases is necessary for clinicians considering appropriate management. There is paucity of formulated guidelines for management of pregnancy-induced hypertension at term. So, such studies in low-resource settings will be of great value in synthesizing evidence regarding an ideal predictor and management of women with pregnancy-induced hypertension at term.

\section{AIMS AND OBJECTIVES}

- To estimate serum $\beta$-hCG and serum lipid profile levels between 12 and 24 weeks of pregnancy and to assess the predictive value of raised $\beta$-hCG levels and dyslipidemia in development of pregnancy-induced hypertension in antenatal women

- To study pregnancy outcome

- To correlate the maternal and neonatal outcome with levels of serum $\beta$-hCG and serum lipids in pregnancyinduced hypertension.

\section{MATERIALS AND METHODS}

This hospital-based prospective cohort study and timebound study of analysis of serum $\beta$-hCG and serum lipids in early second trimester as a predictor of pregnancyinduced hypertension in 400 antenatal women admitted to the obstetric ward and labor room of a rural, tertiary care hospital was carried out in the Department of Obstetrics and Gynecology over 2 years from October 1, 2013 to October 31, 2015 after obtaining permission from the Institutional Ethics Committee.

\section{SELECTION OF SUBJECTS}

Consecutive antenatal women with 12 to 24 weeks of gestation and willing to participate in the study and deliver at the tertiary care center were assessed and enrolled in the study as per the formulated inclusion and exclusion criteria.

\section{Inclusion Criteria}

- 18 to 30 years old primi/multigravidae with singleton pregnancy with gestational age of 12 to 24 weeks as determined by last menstrual period or by ultrasound scan
- Antenatal women with first trimester blood pressure record suggestive of normal blood pressure

- Women willing to participate in the study and ready to deliver in this hospital.

\section{Exclusion Criteria}

- Antenatal women with chronic hypertension

- Antenatal women with diabetes mellitus

- Antenatal women with congenital anomalies

- Antenatal women with multiple gestations.

\section{Evaluation}

Particulars of all antenatal women attending the outpatient department as well as women admitted to the obstetric ward and labor room were noted, such as name, age, symptoms, menstrual history for menarche, last menstrual period, and obstetrical history was asked for gravidity, parity, abortions, preeclampsia in previous pregnancies, gestational diabetes mellitus, growth restriction, low birth weight, prematurity, late pregnancy losses, and neonatal deaths in previous pregnancies. Past medical history was asked for associated medical disorders like diabetes, thyroid and autoimmune disorders. Significant surgical history, family history, and diet and nutrition history were also asked.

A thorough clinical examination including height, weight, pulse, pedal edema, thyroid enlargement, etc., was done.

Blood pressure was measured as per the guidelines for measuring blood pressure during pregnancy. ${ }^{4}$

This was followed by systemic examination. In the obstetrical examination, gestational age, presentation, amount of liquor were noted and fetal heart sounds were auscultated with fetoscope.

All patients were critically evaluated for gestational age depending upon their last menstrual period, regularity of menstrual cycle, clinical examination details, or early ultrasound scan. Routine antenatal investigations like blood group and Rh typing, human immunodeficiency virus, hepatitis B surface antigen, Venereal Disease Research Laboratory, sickling, serum thyroid-stimulating hormone, postglucose blood sugar, urine for albumin and microscopy, and specific investigations like serum $\beta$-hCG level and serum lipid profile were sent between 12 and 24 weeks of gestation.

Ultrasonography was done in:

- First trimester: dating and viability

- Second trimester: anomalies, fetal growth, and placental localization

- Third trimester: fetal growth, liquor, fetal well-being, placenta, Doppler for intrauterine growth restriction, and preeclampsia. 
All antenatal women were followed up monthly till 28 weeks, biweekly till 28 to 36 weeks, and weekly after 36 weeks till delivery and postpartum for 7 days. During follow-up, blood pressure was monitored in every visit. The diagnosis of pregnancy-induced hypertension was done according to the criteria set by National High Blood Pressure Education Program (NHBPEP). ${ }^{4}$ Women with preeclampsia were managed as per hospital protocol. Assessment of serum $\beta$-hCG and serum lipids and their predictability for development of pregnancy-induced hypertension and its effect on maternal and fetal outcome were noted. Further, the maternal and neonatal outcomes were correlated with levels of serum $\beta$-hCG and serum lipids in pregnancy-induced hypertension.

\section{Statistical Analysis}

After data collection, it was entered in an Excel worksheet. All data analysis was done with the help of Statistical Package for the Social Sciences 15 version EPI Info Software version 7 . The continuous quantitative data were summarized as mean and standard deviation, while discrete (categorical) data in numbers and percentage (\%).

The continuous variables [lipid profile-TC, TC, HDLcholesterol, VLDL-cholesterol, LDL-cholesterol; blood pressure-systolic blood pressure (SBP) and diastolic blood pressure (DBP)] were compared by independent Student's t-test. The categorical variables were compared by chisquare $\left(\chi^{2}\right)$ test. Univariate binary logistic regression analysis was used to find out lipid profile-associated risk factors for preeclampsia. The adjusted multivariate logistic regression analysis was carried out further to find out the significant independent predictor for preeclampsia. The univariate and multivariate analysis were done with adjusted demographic variables. A p-value $<0.05$ was considered as significant and $<0.001$ was considered highly significant.

\section{OBSERVATIONS AND RESULTS}

The present study was undertaken to assess the predictability of raised serum $\beta$-hCG and dyslipidemia in second trimester (12-24 weeks) as a predictor of pregnancyinduced hypertension. 400 antenatal women incorporated in the study were followed up till delivery and 7 days postpartum for development of pregnancy-induced hypertension and for pregnancy and labor complications. The relative risk (RR) of raised serum $\beta$-hCG, dyslipidemia, and development of pregnancy-induced hypertension was noted and the maternal and perinatal outcome in women with pregnancy-induced hypertension and normotensive women was analyzed and compared.

During the study period of 2 years, 400 antenatal women were incorporated in the study with serum $\beta$-hCG and lipid profile done at 12 to 24 weeks of gestation.
Of the 400 women, 80 women developed pregnancyinduced hypertension giving the frequency of pregnancyinduced hypertension at a tertiary care center to be $20 \%$.

Most of the women in pregnancy-induced hypertension group and normotensive group belonged to the age group of 22 to 25 years.

Mean age of women in pregnancy-induced hypertension group was $26.13 \pm 3.4079$ and in normotensive group was $25.1875 \pm 2.9726$. As the age advances, incidence of pregnancy-induced hypertension increases.

A total of $47(58.75 \%)$ of antenatal women with pregnancy-induced hypertension were well educated as compared with 228 (71.24\%) normotensive women. The difference between the two study groups was not found to be statistically significant $(p=0.4617)$. There is no correlation between the educational status of women and development of pregnancy-induced hypertension.

A total of 50 (62.5\%) women with pregnancy-induced hypertension and 195 (60.9\%) normotensive women belonged to the middle socioeconomic status. The p-value is 0.797 , which was not significant. Hence, the groups were comparable.

The majority of the women in pregnancy-induced hypertension and normotensive groups were primigravida, 35 (43.75\%) and $148(46.25 \%)$ respectively; 49 $(61.25 \%)$ women with pregnancy-induced hypertension were on mixed diet and 189 (59.06\%) normotensive women were on vegetarian diet. The $p$-value was 0.001 by chi-square test.

The comparison was done of weight gain during pregnancy and body mass index (BMI) for both women with pregnancy-induced hypertension and normotensive women at the time of booking (12-24 weeks of gestation age) and at delivery. The p-value of weight gain during pregnancy ( $p<0.001)$ and BMI ( $p=0.0013)$ was found to be highly significant.

The family history of diabetes mellitus and hypertension was significant in women who developed pregnancyinduced hypertension as compared with normotensive women. The difference between the two groups was statistically significant $(\mathrm{p}=0.0259) ; 73(91.25 \%)$ antenatal women with pregnancy-induced hypertension had pedal edema which in itself is a risk factor for pregnancyinduced hypertension; 219 (68.44\%) of normotensive women had no pedal edema. Both the groups were comparable as the $\mathrm{p}$-value was $<0.001$.

Table 1 shows that the SBP and DBP at the time of booking (12-24 weeks of gestation age) and at delivery were statistically highly significant in women who developed pregnancy-induced hypertension as compared with normotensive women ( $\mathrm{p}$-value $<0.001$ ).

Table 2 shows that women with high serum $\beta$-hCG levels at 12 to 24 weeks of gestation have 1.67 times more 
Table 1: Comparison of SBP and DBP between pregnancy-induced hypertension and normotensive antenatal women at the time of booking (12-24 weeks of gestation age) and at delivery

\begin{tabular}{|c|c|c|c|c|c|}
\hline Blood pressure & & $\begin{array}{l}\text { Pregnancy-induced } \\
\text { hypertension }\end{array}$ & Normotensive & $t$-test & $p$-value \\
\hline \multirow[t]{2}{*}{ Systolic blood pressure } & At booking (12-24 weeks) & $112.85 \pm 9.166$ & $108.71 \pm 9.7323$ & 3.43 & 0.0007 \\
\hline & At delivery & $143.9250 \pm 12.0145$ & $119.4625 \pm 10.1752$ & 18.52 & $<0.001$ \\
\hline \multirow[t]{2}{*}{ Diastolic blood pressure } & At booking (12-24 weeks) & $73.825 \pm 6.546$ & $71.6938 \pm 10.94$ & 1.67 & 0.0963 \\
\hline & At delivery & $94.5250 \pm 9.0609$ & $76.7406 \pm 7.4652$ & 18.22 & $<0.001$ \\
\hline
\end{tabular}

Table 2: Serum $\beta$-hCG and risk of pregnancy-induced hypertension

\begin{tabular}{llllll}
\hline -hCG & $\begin{array}{l}\text { Pregnancy-induced } \\
\text { hypertension }\end{array}$ & Normotensive & Total & $R R$ & $95 \% \mathrm{Cl}(\mathrm{p}$-value $)$ \\
\hline High $(>30,000)$ & $25(31.25 \%)$ & $68(21.25 \%)$ & 93 & 1.67 & $1.03-2.61(0.035)$ \\
Low $(<10,000)$ & $23(28.75 \%)$ & $88(27.50 \%)$ & 111 & 1.27 & $0.783-2.05(0.334)$ \\
Normal $(10,000-30,000)$ & $32(40 \%)$ & $164(51.25 \%)$ & 196 & 1 & - \\
\hline Total & $80(100 \%)$ & $320(100 \%)$ & 400 & & - \\
\hline
\end{tabular}

$\mathrm{Cl}$ : Confidence interval

Table 3: Serum lipid profile and development of pregnancy-induced hypertension

\begin{tabular}{lllcc}
\hline & Pregnancy-induced hypertension & Normotensive & t-test & $p$-value \\
\hline Total cholesterol & $210.1304 \pm 50.7392$ & $178.0908 \pm 47.0994$ & 5.36 & $<0.001$ \\
Triglycerides & $160.2284 \pm 67.3859$ & $135.9886 \pm 66.0728$ & 2.92 & 0.0037 \\
High-density lipoprotein & $44.7034 \pm 8.4007$ & $45.6711 \pm 5.8689$ & -1.20 & 0.2308 \\
Low-density lipoprotein & $134.2065 \pm 47.3392$ & $105.1253 \pm 42.2685$ & 5.37 & $<0.001$ \\
Very low-density lipoprotein & $31.9023 \pm 13.4492$ & $27.5552 \pm 15.1154$ & 2.35 & 0.0193 \\
Total cholesterol/High-density lipoprotein & $4.8224 \pm 1.2232$ & $4.0195 \pm 1.3593$ & 4.82 & $<0.001$ \\
Low-density lipoprotein/High-density lipoprotein & $3.0804 \pm 1.1254$ & $2.3763 \pm 0.9852$ & 5.55 & $<0.001$ \\
\hline
\end{tabular}

risk of developing pregnancy-induced hypertension $(p=0.035)$, whereas low serum $\beta$-hCG has high value, but it was by chance, and there is no association between low serum $\beta$-hCG and pregnancy-induced hypertension $(p=0.334)$. It was found that women with high $\beta$-hCG level had severe pregnancy-induced hypertension and poor maternal and perinatal outcome.

Table 3 shows that dyslipidemia with regard to raised TC, TG, LDL, VLDL, TC/HDL, and LDL/HDL is an important risk factor for the development of pregnancyinduced hypertension. The mean TC level in women with pregnancy-induced hypertension was $210.1304 \pm 50.7392$ as compared with $178.0908 \pm 47.0994$ in normotensive women. The difference in levels of TC $(p<0.001)$, TG $(p=0.0037), \operatorname{LDL}(p<0.001), \operatorname{VLDL}(p=0.0193), T C /$ HDL $(\mathrm{p}<0.001)$, and LDL/HDL $(\mathrm{p}<0.001)$ in both the groups were statistically highly significant. It was found that women with dyslipidemia had severe pregnancy-induced hypertension and poor maternal and perinatal outcome.

The risk of having pregnancy-induced hypertension was 3.08 times more among patients with high TC as compared with low TC levels, 2.38 times more among patients with high TG as compared with normal TG levels, 3.04 times more among patients with high LDL as compared with low LDL levels, 1.79 times more among patients with low HDL as compared with normal HDL levels, 1.54 times more among patients with high VLDL as compared with normal VLDL levels, 2.81 times more among patients with high TC/HDL as compared with normal TC/HDL levels, and 2.67 times more among patients with high LDL/HDL as compared with normal LDL/HDL levels.

Table 4 shows that 9 (11.25\%) women had antepartum accidental hemorrhage, intrapartum DIC, postpartum atonic postpartum hemorrhage and acute renal failure; these were the maternal complications in women with pregnancy-induced hypertension as compared with 2 $(5 \%)$ in normotensive women. The difference in the complications in both the groups was statistically significant.

A total of $23(28.75 \%)$ women delivered vaginally at term in women with pregnancy-induced hypertension as compared with 174 (54.375\%) normotensive women; $57(71.25 \%)$ women had cesarean sections in women with pregnancy-induced hypertension as compared with $146(45.625 \%)$ in normotensive women. There were no instrumental deliveries. The difference in mode of delivery in both the groups was statistically significant $(p=0.0001)$. The most common indication for cesarean section in women with pregnancy-induced hypertension was abnormal Doppler and fetal distress.

A total of $68(85.00 \%)$ of women with pregnancyinduced hypertension delivered at term as compared with $302(94.375 \%)$ in normotensive women. Preterm delivery was necessitated in $12(15 \%)$ in women with 
Serum $\beta-h C G$ and Lipid Profile in Early Second Trimester

Table 4: Distribution of women according to antepartum, intrapartum, and postpartum complications

\begin{tabular}{lllll}
\hline Complications & $\begin{array}{l}\text { Pregnancy-induced } \\
\text { hypertension }\end{array}$ & Normotensive & Frequency & Percent \\
\hline Antepartum-accidental hemorrhage & $1(1.25 \%)$ & $1(2.5 \%)$ & 2 & 0.50 \\
Placenta accreta & $1(1.25 \%)$ & $0(0 \%)$ & 1 & 0.25 \\
Intrapartum DIC & $2(2.50 \%)$ & $0(0 \%)$ & 2 & 0.50 \\
Atonic postpartum hemorrhage & $3(3.75 \%)$ & $1(2.5 \%)$ & 3 & 0.75 \\
Acute renal failure & $2(2.5 \%)$ & $0(0 \%)$ & 2 & 0.50 \\
Normal & $71(88.75 \%)$ & $318(99.37 \%)$ & 389 & 97.20 \\
\hline Total & $80(100 \%)$ & $320(100 \%)$ & 400 & 100 \\
\hline
\end{tabular}

Table 5: Distribution according to fetal outcome

\begin{tabular}{|c|c|c|c|c|}
\hline Fetal outcome & $\begin{array}{l}\text { Pregnancy-induced } \\
\text { hypertension }\end{array}$ & Normotensive & Frequency & Percent \\
\hline $\begin{array}{l}\text { NICU (hyperbilirubinemia, intrauterine growth } \\
\text { restriction, asphyxia, low birth weight) }\end{array}$ & $22(27.5 \%)$ & $21(6.5 \%)$ & 43 & 10.75 \\
\hline Anomalous baby & $0(0 \%)$ & $1(0.312 \%)$ & 1 & 0.25 \\
\hline Intrauterine demise & $2(2.5 \%)$ & $0(0 \%)$ & 2 & 0.50 \\
\hline Normal & $56(70 \%)$ & $298(93.125 \%)$ & 354 & 88.50 \\
\hline Total & $80(100 \%)$ & $320(100 \%)$ & 400 & 100 \\
\hline
\end{tabular}

pregnancy-induced hypertension as compared with $18(5.625 \%)$ in normotensive women. The difference between the two study groups was found to be statistically significant $(\mathrm{p}=0.0075)$.

A total of $44(55 \%)$ women with pregnancy-induced hypertension delivered low birth weight babies as compared with 84 (26.25\%) normotensive women. The mean birth weight in women with pregnancy-induced hypertension was $2.4072 \pm 0.5470$ as compared with $2.6222 \pm 0.3280$ in normotensive women. The difference in the two study groups was found to be highly statistically significant.

Table 5 shows that 24 (30\%) women with pregnancyinduced hypertension had adverse fetal outcomes as compared with $22(6.812 \%)$ in normotensive women. The difference between the two study groups was highly significant.

\section{DISCUSSION}

Hypertensive disorders of pregnancy are one of the most common complications of pregnancy and affects up to $8 \%$ of all gestations. ${ }^{5}$ Pregnancy-induced hypertension, hemorrhage, and infection form a deadly triad contributing greatly to maternal morbidity and mortality rates.

The exact mechanism of pregnancy-induced hypertension is unknown, no standards for prediction exist, and most facets of management are unclear, so management of pregnancy-induced hypertension remains challenging and controversial.

Reduction of maternal and perinatal mortality and morbidity due to pregnancy-induced hypertension is the high priority in international community, it being one of the millennium development goals.
Placenta is the known primary trigger of pregnancyinduced hypertension. Pathophysiological placental abnormalities are seen consistently to be associated with pregnancy-induced hypertension. Women with pregnancy-induced hypertension have hyperplacentosis or an abnormal placentation. ${ }^{6}$ Hypoxic placental damage caused by hypertensive disorders result in relative hyperplasia of cytotrophoblastic cell and increased hormone $\beta$-hCG.

Maternal plasma lipids are significantly elevated during pregnancy. Abnormal lipid metabolism in early pregnancy could be one of the factors for the development of pregnancy-induced hypertension. Dyslipidemia may impair trophoblast invasion. Altered lipid synthesis leading to decrease in prostaglandin I2:TXA2 ratio is supposed to be an important way of pathogenesis in pregnancy-induced hypertension. ${ }^{7}$

Over the last decade, there has been enhanced awareness of predictors. Despite so many predictors, due to lack of larger randomized trials, the search is still on for an ideal predictor.

Since the etiology is obscure, controversies in management prevail, leaving the clinician in a quandary.

In the present study, the frequency of pregnancy-induced hypertension at a tertiary care center was found to be $20 \%$.

Table 6 shows that the frequency in our study is similar to studies by Vidyabati et $\mathrm{al}^{6}(17.68 \%)$, Singh et $\mathrm{al}^{8}(21.48 \%)$, Ephraim et $\mathrm{al}^{9}(54.54 \%)$, Yadav et $\mathrm{al}^{10}$ $(17.5 \%)$, Siddiqui et $\mathrm{al}^{11}(33.33 \%)$, Remzi et $\mathrm{al}^{12}(38.23 \%)$ and Wander ${ }^{13}(23.636 \%)$.

\section{Serum B-hCG}

Table 7 shows that in a study by Vidyabati et $\mathrm{al}^{6}$ and Wander, ${ }^{13}$ the levels of serum $\beta$-hCG were high, 45103.45 
Table 6: Frequency of pregnancy-induced hypertension

\begin{tabular}{ll}
\hline Studies & Frequency (\%) \\
\hline Vidyabati et al $^{6}$ & 17.68 \\
Singh et al $^{8}$ & 21.481 \\
Ephraim et al $^{9}$ & 54.54 \\
Yadav et al $^{10}$ & 17.5 \\
Siddiquii & 33.33 \\
Remzi et al $^{12}$ & 38.23 \\
Wander $^{13}$ & 23.636 \\
Our study & 20 \\
\hline
\end{tabular}

\pm 17028.01 and $60375 \pm 38843$ respectively. In the study of Remzi et al ${ }^{12}(33960 \pm 4048.74)$, it was comparable to our study $(24967.93 \pm 24021.36)$.

\section{Lipid Profile}

Table 8 shows in a study by Vidyabati et $\mathrm{al}^{6}$ and Singh et $\mathrm{al}^{8}{ }^{8}$ the level of serum lipid profile was high as compared with our study. The study by Yadav et $\mathrm{al}^{10}$ and Wander ${ }^{13}$ was comparable with our study.

\section{Maternal Outcome}

In our study, 9 (11.25\%) women had antepartum accidental hemorrhage, intrapartum DIC, and postpartum atonic postpartum hemorrhage and acute renal failure; these were the maternal complications in women with pregnancy-induced hypertension as compared with 2 $(5 \%)$ in normotensive women. The study conducted by Vrijkotte et $\mathrm{al}^{14}$ had pregnancy-induced hypertension in $4.9 \%$ and preeclampsia in $3.7 \%$ women. And in the study by Wander, ${ }^{13} 2$ (7.69\%) had eclampsia and $18(22.5 \%)$ women had preeclampsia.

\section{Fetal Outcome}

In the present study, 24 (30\%) women with pregnancyinduced hypertension had adverse fetal outcomes as compared with $22(6.812 \%)$ in normotensive women. The indications for neonatal intensive care unit (NICU) admission were hyperbilirubinemia, intrauterine growth restriction, asphyxia, and low birth weight. Most common being asphyxia indicated by low APGAR score; $12(15 \%)$ were preterm and 44 (55\%) were low birth weight. The study conducted by Vrijkotte et $\mathrm{al}^{14}$ showed
Table 7: Serum $\beta$-hCG

\begin{tabular}{lll}
\hline Studies & $\begin{array}{l}\text { Pregnancy-induced } \\
\text { hypertension }\end{array}$ & Normotensive \\
\hline Vidyabati et al $^{6}$ & $45103.45 \pm 17028.01$ & $21762.39 \pm 6133.92$ \\
Remzi et al $^{12}$ & $33960 \pm 4048.74$ & $18634 \pm 1618.7$ \\
Wander $^{13}$ & $60375 \pm 38843$ & $21260 \pm 9565$ \\
Our study & $24967.93 \pm 24021.36$ & $21044.13 \pm 16323.19$ \\
\hline
\end{tabular}

that there were $5.3 \%$ preterm and $9.3 \%$ were small for gestational age.

\section{CONCLUSION}

Pregnancy-induced hypertension is still a little understood entity, despite the enormous impact of its complications on maternal and fetal outcomes.

The above study concludes that the frequency of pregnancy-induced hypertension at a tertiary care hospital is $20 \%$.

High serum $\beta$-hCG levels and dyslipidemia are high risk factors which help us in the prediction of pregnancyinduced hypertension. Women with high serum $\beta$-hCG levels estimation at 12 to 24 weeks of gestation have 1.67 times ( $R R=1.67)$ risk of developing pregnancy-induced hypertension. Women with dyslipidemia (high levels of TC, TG, LDL, VLDL, TC/LDL) at 12 to 24 weeks of gestation have a risk of developing pregnancy-induced hypertension.

However, considering the percentage of detection, the divergent point of serum $\beta$-hCG, wide range of cut-off values, dyslipidemia is a better predictor of pregnancyinduced hypertension in second trimester. The maternal and perinatal outcome was directly proportional to levels of serum $\beta$-hCG and lipid profile.

As maternal and perinatal morbidity is directly related to diagnosis and management of pregnancy-induced hypertension, serum $\beta$-hCG and lipid profile should be considered during risk-based counseling. Women at increased risk of pregnancy hypertension are most commonly identified by personal or family history of high DBP, chronic medical disease, and/or abnormal uterine Doppler before 24 weeks. Combining various clinical, biochemical and/or ultrasonographic risk markers may better identify women at increased risk; however, no interventional trial has used such an approach to evaluate preventative therapy.

Table 8: Serum lipid profile

\begin{tabular}{lllll}
\hline Studies & Total cholesterol & Triglycerides & $\begin{array}{l}\text { High-density } \\
\text { lipoprotein }\end{array}$ & $\begin{array}{l}\text { Low-density } \\
\text { lipoprotein }\end{array}$ \\
\hline Vidyabati et al $^{6}$ & $237.19 \pm 33.95$ & $213.94 \pm 51.07$ & $48.88 \pm 11.76$ & $135.47 \pm 27.12$ \\
Singh et al $^{8}$ & $230.48 \pm 46.69$ & $207.76 \pm 47.31$ & $31.33 \pm 11.81$ & $147.64 \pm 20.29$ \\
Yadav et al $^{10}$ & $204.14 \pm 40.13$ & $167.24 \pm 50.68$ & $51.86 \pm 10.97$ & $121.9 \pm 34.3$ \\
Wander $^{13}$ & $225 \pm 41$ & $128 \pm 40$ & $47 \pm 11$ & $42.50 \pm 11.93$ \\
Our study & $210.130 \pm 50.73$ & $160.228 \pm 67.38$ & $44.70 \pm 8.4007$ & $130 \pm 25$ \\
\hline
\end{tabular}


Art of good obstetric care involves balance between vaginal delivery and cesarean sections. Randomized control trials have concluded that planned births at 37 weeks of gestation improves maternal and perinatal outcomes which are in accordance with our study. Hence, induction of labor and aggressive management are the corner stones for management of pregnancy-induced hypertension.

Thus, imparting knowledge regarding healthy pregnancy during antenatal care, screening for at-risk women by predictors, and timely treatment may help in reducing maternal and perinatal complications.

\section{REFERENCES}

1. Duley L. The global impact of preeclampsia and eclampsia. Semin Perinatol 2009 Jun;33(3):130-137.

2. Sibai BM. Diagnosis and management of gestational hypertension and preeclampsia. Am J Obstet Gynecol 2003 Jul;102(1): 181-192.

3. Brazy JE, Grimm JK, Little VA. Neonatal manifestations of severe maternal hypertension occurring before the thirty-sixth week of pregnancy. J Pediatr 1982 Feb;100(2):265-271.

4. Gifford RW, August PA, Cunningham G, Green LA, Lindheimer MD, McNellis D, Roberts JM, Roccella EJ, Sibai BM, Taler SJ. National high blood pressure education program: working group on high blood pressure in pregnancy. Am J Obstet Gynecol 2000 Jul;183(1):S1-S22.

5. Sibai BM. Diagnosis and management of gestational hypertension and preeclampsia. Obstet Gynecol 2003 Jul;102(1): 181-192.
6. Vidyabati RK, Davina H, Singh NK, Gyaneshwar SW. Serum beta human chorionic gonadotropin ( $\beta \mathrm{hCG}$ ) and lipid profile in early second trimester as predictors of pregnancy induced hypertension. J Obstet Gynecol India 2010 Jan-Feb;60(1):44-50.

7. Robson, SC. Hypertension and renal disease in pregnancy. In: Edmonds DK, editor. Dewhurst's textbook of obstetrics and gynaecology for postgraduates. 6th ed. New York: Blackwell Science; 1999. pp. 167-169.

8. Singh U, Yadav S, Mehrotra S, Natu SM, Kumari K, Yadav YS. Serum lipid profile in early pregnancy as predictor of preeclampsia. Int J Med Res Rev 2013 Apr-Jun;1(2):56-62.

9. Ephraim R, Doe P, Amoah S, Antoh E. Lipid profile and high maternal body mass index is associated with preeclampsia: a case-control study of the Cape Coast Metropolis. Ann Med Health Sci Res 2014 Sep;4(5):746-750.

10. Yadav K, Aggarwal S, Verma K. Serum beta hCG and lipid profile in early second trimester as predictors of pregnancy induced hypertension. J Obstet Gynaecol India 2014 Jun;64(3):169-174.

11. Siddiqui IA. Maternal serum lipids in women with pre eclampsia. Ann Med Health Sci Res 2014 Jul;4(4):638-641.

12. Remzi G, Erdal A, Nursel B, Ozcan B. Elevated serum beta hCG levels in severe preeclampsia. Turk J Med Sci 2000;30: 43-45.

13. Wander, G. Can early second trimester serum beta hCG, serum cholesterol and triglycerides be markers of subsequent hypertensive disorders of pregnancy (HDP). Liverpool: RCOG World Congress; 2013.

14. Vrijkotte TG, Krukziener N, Hutten BA, Vollebregt KC, van Eijsden M, Twickler MB. Maternal lipid profile during early pregnancy and pregnancy complications and outcomes: the ABCD study. J Clin Endocrinol Metab 2012 Nov;97(11): 3917-3925. 